\title{
Characterization, activity, and computer modeling of a molecular inclusion complex containing rifaldazine
}

This article was published in the following Dove Press journal:

International Journal of Nanomedicine

30 January 2013

Number of times this article has been viewed

\section{Qunyou Tan ${ }^{1, *}$ \\ Dan $\mathrm{He}^{2, *}$ \\ Mingjun $\mathrm{Wu}^{2, *}$ \\ Lin Yang ${ }^{3}$ \\ Yong Ren ${ }^{4}$ \\ Juan $\mathrm{Liu}^{2}$ \\ Jingqing Zhang ${ }^{2}$}

'Department of Thoracic Surgery, Institute of Surgery Research, Daping Hospital, Third Military Medical University, Chongqing, ${ }^{2}$ Medicine Engineering Research Center, Chongqing Medical University, Chongqing, ${ }^{3}$ Chongqing Institute for Food and Drug Control, Chongqing, ${ }^{4}$ Center of Drug Discovery, Nanjing Normal University, Nanjing, People's Republic of China

*These authors contributed equally to this work
Correspondence: Jingqing Zhang Medicine Engineering Research Center, Chongqing Medical University, 50 I Building 22, Jingdi Garden, 6 Dahuang Road, Yuzhong District, Chongqing 400042, People's Republic of China Tel +86 I3308300303

Fax +862368767988

Email zjqrae0I@I63.com
Background: The purpose of this study was to develop, characterize, and investigate a molecular inclusion complex containing rifaldazine with good solubility and antibacterial activity.

Methods: Rifaldazine, a lipophilic molecule, was encapsulated into the hydrophobic cavity of $\beta$-cyclodextrin to form a molecular inclusion complex (RAABCD) with good solubility. RAABCD was prepared in a short time using a solid-state grinding method. The inclusion ratio, binding constant, and change in Gibbs free energy were determined by a phase solubility diagram and/or ultraviolet-visible spectroscopy. Differential scanning calorimetry and Fourier transform infrared spectroscopy of RAABCD were performed. Morphological features of RAABCD were observed by photomicroscopy. The most likely optimal configuration for RAABCD was simulated by computer modeling. Broth macrodilution testing was done to investigate the antibacterial activity of RAABCD.

Results: The inclusion ratio, binding constant, and change in Gibbs free energy, determined by a phase solubility diagram and/or ultraviolet-visible spectroscopy were $1: 1,288.33 / 261.33 \mathrm{~L} / \mathrm{mol}$, and 32.29/31.73 kJ/mol, respectively. Differential scanning calorimetry and Fourier transformed infrared spectra of RAABCD confirmed the molecular interaction between rifaldazine and $\beta$-cyclodextrin. The morphological difference between irregular and amorphous-shaped RAABCD and columnar-shaped rifaldazine further confirmed the molecular encapsulation of rifaldazine. The most likely optimal configuration for RAABCD was confirmed by computer modeling. Broth macrodilution testing indicated that RAABCD had good antibacterial activity.

Conclusion: RAABCD had improved solubility and good activity, and might be a promising alternative for treatment of a range of bacterial infections.

Keywords: rifaldazine, cyclodextrin inclusion complex, stoichiometric relationships, differential scanning calorimetry, Fourier transform infrared spectra, computer modeling

\section{Introduction}

Rifaldazine, one of the most clinically effective antibiotics, is a semisynthetic product (Figure 1A) derived from Amycolatopsis rifamycinica. Being an inhibitor of bacterial DNA-dependent RNA polymerase, rifaldazine inhibits bacterial RNA synthesis, retards bacterial growth, and kills bacteria. Rifaldazine has been shown to be effective against Mycobacterium infections (such as tuberculosis and Hansen's disease), other bacterial infections (such as methicillin-resistant Staphylococcus aureus, osteomyelitis, and prosthetic joint infections), and vaccinia virus. ${ }^{1,2}$ Rifaldazine is also used as a prophylactic agent for meningococcal infection. ${ }^{3}$ However, taking tuberculosis treatment as an example, being an antibiotic with poor solubility and low stability, rifaldazine must 


\section{A}

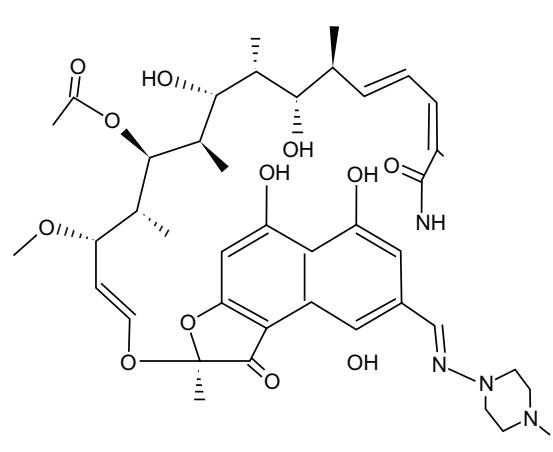

B

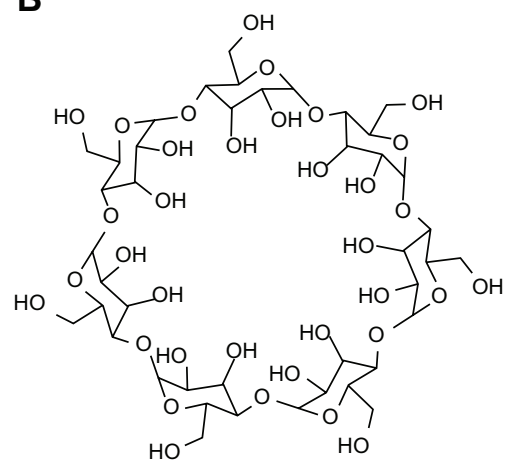

Figure I Chemical structure of $(\mathbf{A})$ rifaldazine and (B) $\beta$-cyclodextrin.

be administered at a high daily dose continuously for several months, with adverse effects such as hepatitis, breathlessness, flushing, nausea, and headache. ${ }^{4,5}$ Therefore, attempts have been made in recent decades to develop alternative delivery systems for rifaldazine, including liposomes ${ }^{6}$ and microspheres ${ }^{7}$ for injection, cyclodextrin complexes, ${ }^{8}$ chitosomes, ${ }^{9}$ and liposomes ${ }^{10}$ for lung nebulization. Disadvantages of these rifaldazine delivery systems include inconvenient administration, a complex manufacturing process, and uncertain safety.

A molecular inclusion complex refers to a complex compound or an unbonded association in which a guest molecule (usually a low molecular weight lipophilic drug) is contained wholly or partially within the lipophilic interior cavity of a host molecule (frequently a cyclodextrin). $\beta$-cyclodextrin (Figure 1B) is a cyclic oligosaccharide composed of seven glucopyranose units joined through $\alpha$-1,4-glucosidic bonds, and is typically considered to be a truncated cone-shaped molecule with a hydrophilic external surface. ${ }^{11}$ Being a nontoxic and cost-effective pharmaceutical excipient with favorable features, $\beta$-cyclodextrin is recorded in several pharmacopoeias including the United States Pharmacopoeia, British Pharmacopoeia, and Chinese Pharmacopoeia. The safety and cost-effectiveness of $\beta$-cyclodextrin (its price is much lower than for chemically modified $\beta$-cyclodextrin) are well known. The inclusion complexation of $\beta$-cyclodextrin molecular technology has been successfully utilized to increase the solubility and/or stability of some insoluble and/or labile drugs. ${ }^{12}$ The pharmaceutical industry has already marketed a few $\beta$-cyclodextrin molecular inclusion complexes, including $\mathrm{Cicladol}^{\circledR}$ (containing piroxicam, a nonsteroidal antiinflammatory drug) by Masterpharma (Chiesi, Italy), Ulgut ${ }^{\circledR}$ (containing benexate, an anti-ulcer drug) by Teikoku (San Jose, CA), and Surgamyl ${ }^{\circledR}$ (containing tiaprofenic acid, an analgesic) by Roussel-Maestrelli (Italy). ${ }^{13}$ Although it is currently unavailable for clinical use, $\beta$-CD molecular inclusion complexes of RAA (RAABCD) have already aroused people's interest. It was documented in a United States patent that the RAABCD with higher solubility (twice that of free rifaldazine) could be prepared in spite of the fact that it must take a very long time (5-8 hours) to complete the preparation process. ${ }^{14}$

In addition to the above-mentioned considerations, we chose to investigate $\beta$-cyclodextrin over its derivatives for the following reasons. Although a lot of modified $\beta$-cyclodextrins were available on the market, none except hydroxypropyl- $\beta$-cyclodextrin (HCD) had been recorded in a pharmacopoeia, and all modified $\beta$-cyclodextrins (including HCD) were more expensive than the parent compound. Further, the safety of the modified $\beta$-cyclodextrins, except for $\mathrm{HCD}$, was either inferior to that of $\beta$-cyclodextrin or needed further investigation of safety in oral use. HCD has been mainly used to prepare various injectable formulations so far. The reason why HCD is seldom used to prepare the oral formulation is partly due to the high price of HCD. In addition, although HCD had better aqueous solubility, it was not expected to have better solubilization effects than the parent compound, $\beta$-cyclodextrin. Also, earlier researchers ${ }^{15}$ had found that the solubilization effects of HCD on diazepam, digoxin, indomethacin, and hydroprednisone were much lower than that of $\beta$-cyclodextrin. In our preliminary study, we found that the solubility of RAAHCD and RAABCD was 2.5 and 4.4 times that of free rifaldazine, respectively (RAAHCD data not shown). Based on the above information, RAABCD were the most feasible and therefore more likely to be produced and marketed by the pharmaceutical industry and used in future clinical practice.

In this study, RAABCD with a solubility 4.4 times that of free rifaldazine was prepared in just 30 minutes using a solid-state grinding method. RAABCD was characterized by differential scanning calorimetry and Fourier transform 
infrared (FTIR) spectroscopy. The physical properties and antibacterial activity of RAABCD, including its complex stoichiometry (inclusion ratio, binding constant, and change in Gibbs free energy), microscopic morphology, configuration simulation, interaction energy, and minimum inhibitory concentration were investigated. Our findings indicate that RAABCD enhanced the physical properties of rifaldazine and had good antibacterial activity.

\section{Materials and methods Materials}

Rifaldazine (purity $\geq 97.0 \%$ ) was purchased from Shuainuo Medicine Supplement Co, Ltd (Shanxi, People's Republic of China). $\beta$-cyclodextrin (purity $\geq 98.0 \%$ ) was obtained from Xinxin Pharmaceutical Excipients Co, Ltd (Taixing, People's Republic of China). All other chemicals and solvents were of analytical grade.

\section{Phase solubility study}

An excess amount of rifaldazine was added to $\beta$-cyclodextrin solutions of different concentrations (0-15.18 mmol/L). The resulting suspensions were sonicated for 5 minutes and shaken $(100 \mathrm{rpm})$ for 5 hours in a water bath at $25^{\circ} \mathrm{C} \pm 0.5^{\circ} \mathrm{C}$ until solubility equilibrium was established. Next, the suspensions were filtered through Millipore membrane filters ( $0.45 \mu \mathrm{m}$ pore size). The filtrate was analyzed at $474 \mathrm{~nm}$ using an ultraviolet-visible spectrophotometer (UV-2501PC, Shimadzu, Kyoto, Japan). The binding constant $\left(K_{\mathrm{b}}\right)$ was calculated from a phase solubility diagram with the assumption of $1: 1$ stoichiometry using the following equation: ${ }^{16,17}$

$$
K_{\mathrm{b}}=\left[S_{\mathrm{p}} / S_{\mathrm{o}}\left(1-S_{\mathrm{p}}\right)\right]
$$

where $S_{\mathrm{p}}$ is the slope of the phase solubility curve (Figure 2A) and $S_{\mathrm{o}}$ is the intrinsic solubility of rifaldazine.

The change in Gibbs free energy $\left(\Delta G^{0}\right)$ on transfer of rifaldazine from aqueous solution to the cavity of $\beta$-cyclodextrin was calculated using the following equation: ${ }^{18}$

$$
\Delta G^{0}=-2.303 R T \log K_{\mathrm{b}}
$$

where $S_{\mathrm{o}}$ and $S_{\mathrm{s}}$ are the solubility of rifaldazine in the absence and presence of $\beta$-cyclodextrin, respectively.

\section{Determination of inclusion ratio using a continuous variation method}

Various volumes of equimolar concentrations of rifaldazine and aqueous $\beta$-cyclodextrin solution were mixed such that the total molar concentrations of rifaldazine and $\beta$-cyclodextrin were kept constant and the molar fraction of rifaldazine (the numerator was the molar value of rifaldazine, the denominator was the sum of molar value of $\beta-C D$ and molar value of rifaldazine) varied from 0.1 to $0.9 .{ }^{19}$ Absorbance values for the mixed solutions $\left(A_{1}\right)$ and the corresponding concentrations of free rifaldazine solution $\left(A_{2}\right)$ were measured separately at $474 \mathrm{~nm}$. The difference in absorbance $\left(\Delta A=A_{2}-A_{1}\right)$ was then plotted against the molar fraction. The molar fraction corresponding to the maximum difference in absorbance was considered to be the optimal inclusion ratio.

\section{Determination of binding constant by ultraviolet-visible spectroscopy}

Various quantities of rifaldazine and $\beta$-cyclodextrin were simultaneously dissolved in distilled water to obtain a series of solutions containing the same concentration of rifaldazine $\left(2.43 \times 10^{-5} \mathrm{~mol} / \mathrm{L}\right)$ and different concentrations of $\beta$-cyclodextrin $\left(0-1.52 \times 10^{-2} \mathrm{~mol} / \mathrm{L}\right)$. These solutions were then analyzed by ultraviolet-visible spectrophotometry, and the absorbance values $\left(A_{i}\right)$ were recorded individually. Each experiment was done in triplicate. When the complex stoichiometry was $1: 1$, the apparent binding constant $K_{\mathrm{b}}$ could be calculated using the following equation:

$$
\frac{1}{\Delta A_{i}}=\frac{1}{\Delta \varepsilon K_{b}[\beta-C D]_{i}[R A A]}+\frac{1}{\Delta \varepsilon[R A A]}
$$

If $1 / \Delta A_{i}$ was plotted against $1 /[\beta-C D]_{i}, K_{\mathrm{b}}$ could be calculated from the linear regression intercept and slope according to the following equation:
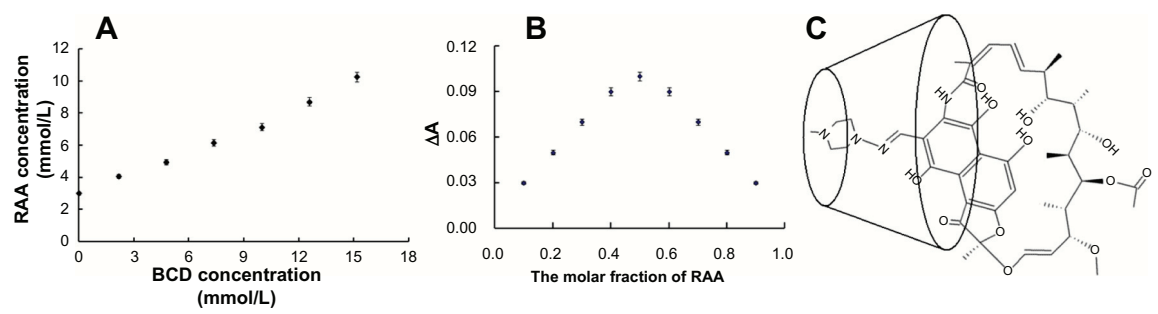

Figure 2 Phase solubility diagram $(\mathbf{A})$ of RAABCD. Continuous variation plot $(\mathbf{B})$ of RAABCD. The data represent the mean \pm standard deviation $(n=6)$. The proposed structure model (C) of RAABCD with I:I stoichiometry.

Abbreviation: RAABCD, $\beta$-cyclodextrin molecular inclusion complexes of rifaldazine. 


$$
K_{\mathrm{b}}=\frac{\text { Intercept }}{\text { Slope }}
$$

where $\Delta A_{i}$ is the difference in absorbance $\left(\Delta A_{i}=A_{0}-A_{i}\right)$ of the rifaldazine solution in the absence $\left(A_{0}\right)$ and presence $\left(A_{i}\right)$ of $\beta$-cyclodextrin, $\Delta \varepsilon$ is the difference between the molar absorption coefficient $\left(\Delta \varepsilon=\varepsilon_{0}-\varepsilon_{R A A}\right)$ of the rifaldazine solution in the absence $\left(\varepsilon_{0}\right)$ and presence $\left(\varepsilon_{i}\right)$ of $\beta$-cyclodextrin, and $[\beta \text {-cyclodextrin }]_{i}$ and $[R A A]$ are the concentrations of $\beta$-cyclodextrin and RAA, respectively. ${ }^{20}$

\section{Preparation of RAABCD}

RAABCD was prepared using a solid-state grinding method. Equimolar amounts of rifaldazine and $\beta$-cyclodextrin were triturated separately by mortar and pestle for 3 minutes, and then mixed followed by grinding for 30 minutes at $25^{\circ} \mathrm{C}$.

\section{Differential scanning calorimetry}

The samples (rifaldazine, $\beta$-cyclodextrin, RAABCD, physical mixture) were analyzed using a differential scanning calorimeter (STA 449C, Netzsch, Selb, Germany). The samples were sealed in an aluminum crimp cell and heated at a rate of $10^{\circ} \mathrm{C}$ per minute from $30^{\circ} \mathrm{C}$ to $350^{\circ} \mathrm{C}$ under nitrogen gas. ${ }^{21}$

\section{FTIR spectroscopy}

The samples (rifaldazine, $\beta$-cyclodextrin, RAABCD, physical mixture) were mixed with $\mathrm{KBr}$ powder and analyzed using an FTIR spectrometer (Nicolet 380, Thermo Electron Scientific Instruments, Madison, WI) at a resolution of $4 \mathrm{~cm}^{-1} .22$

\section{Solubility study}

An excess amount of RAABCD was added to $50 \mathrm{~mL}$ of distilled water and stirred for 60 minutes at $25^{\circ} \mathrm{C}$ until equilibrium was reached. The resulting suspension was filtered through a Millipore membrane filter $(0.45 \mu \mathrm{m}$ pore size $)$, and the filtrate was investigated at $474 \mathrm{~nm}$ with an ultravioletvisible spectrometer (UV-5130, Shimadzu). ${ }^{23}$

\section{Morphological features}

The surface morphology of the sample powders (rifaldazine, $\beta$-cyclodextrin, RAABCD, physical mixture) was observed using a biological microscope (XSP-35-1600X, Phoenix, Shangrao, People's Republic of China) and images were taken with a camera (C-60 Zoom, Olympus, Hong Kong, People's Republic of China).

\section{Computer modeling}

The chemical structures of rifaldazine and $\beta$-cyclodextrin were simulated using a CAChe 6.18 Worksystem Pro version 5.0 (Fujitsu Limited, Tokyo, Japan). The minimum energies of rifaldazine and $\beta$-cyclodextrin before and after inclusion were estimated separately, and the energy change (ie, binding energy) was then calculated to compute the most likely optimal configuration of RAABCD.

\section{Antibacterial activity}

The broth macrodilution method was used to test the antibiotic susceptibility of S. aureus ATCC25 923 and Escherichia coli ATCC25 922 according to standard procedures used in the laboratory. ${ }^{24}$ Briefly, RAABCD and free rifaldazine were separately dissolved in sterile distilled water and diluted with Mueller-Hinton culture medium to obtain a series of culture media containing different rifaldazine concentrations $(0.125$, $0.25,0.5,1,2,4,8,16,32,64,128$, and $256 \mu \mathrm{g} / \mathrm{mL})$. These culture media were then inoculated with $S$. aureus and $E$. coli for 24 hours at $37^{\circ} \mathrm{C}$, respectively. Pure Mueller-Hinton culture medium inoculated with the corresponding bacterium was used as the positive reference. The antibacterial activity was observed by visual inspection of the bacterial lawn. The minimal inhibitory concentration was the lowest drug concentration at which no visible growth of bacteria was observed.

\section{Results and discussion \\ Stoichiometric relationships}

The inclusion ratio and binding constant, two key characteristics of molecular inclusion complexes, are usually determined by the phase solubility diagram method. However, ultravioletvisible spectroscopy is also suitable for determination of these parameters if the encapsulated drug has an appropriate ultraviolet-visible absorption spectrum. Firstly, a phase solubility study was carried out. The phase solubility curve (Figure 2A) indicated that the concentration of rifaldazine increased with increasing $\beta$-cyclodextrin concentration in a linear fashion $\left(\mathrm{C}_{[\mathrm{RAA} \text { concentration }]}=0.4638 \times \mathrm{C}_{[\mathrm{B}-\mathrm{CD} \text { concentration }]}+2.8789\right.$, $\left.r^{2}=0.9917\right)$. The phase solubility diagram was characterized as being of $A_{L}$ type, suggesting formation of the RAABCD complex with a 1:1 molar ratio of rifaldazine to $\beta$-cyclodextrin. The binding constant $\left(K_{\mathrm{b}}\right)$ can reflect the strength of the binding force between rifaldazine and $\beta$-cyclodextrin molecules. The $K_{\mathrm{b}}$ value of RAABCD calculated according to equation (1) was $288.33 \pm 2.79 \mathrm{~L} / \mathrm{mol}$ (mean \pm standard deviation, $\mathrm{n}=3$ ) $>200 \mathrm{~L} / \mathrm{mol}$, further suggesting that rifaldazine could be complexed with $\beta$-cyclodextrin and become a more soluble and stable complex. ${ }^{20}$ The spontaneity and feasibility of the molecular complexation of rifaldazine and $\beta$-cyclodextrin were further evaluated using the thermodynamic approach. The change in Gibbs free energy $\left(\Delta G^{0}\right)$ on transfer of rifaldazine 
from aqueous solution to the cavity of $\beta$-cyclodextrin calculated according to equation (2) was $-32.29 \mathrm{~kJ} / \mathrm{mol}$. The negative value of the energy change indicated energetically favorable conditions for complexation. Secondly, the inclusion ratio was obtained by the classic continuous variation method used to determine complex stoichiometry experimentally. As shown in Figure 2B, the molar fraction of rifaldazine corresponding to the maximum difference of absorbance was 0.5 , indicating that the inclusion ratio was $1: 1$. This inclusion ratio was the same as that obtained in the phase solubility study. The above results, considered together with the differential scanning calorimetry and FTIR spectroscopy results described later, indicate that the rifaldazine molecule can enter and remain in the $\beta$-cyclodextrin cavity (Figure $2 \mathrm{C}$ ). Thirdly, the binding constant $\left(K_{\mathrm{b}}\right)$ of RAABCD was determined by ultraviolet-visible spectroscopy. The $K_{\mathrm{b}}$ value calculated by equation (3) and (4) was $261.33 \pm 2.79 \mathrm{~L} / \mathrm{mol}(\mathrm{n}=3)$, so was a little lower than that of $288.33 \mathrm{~L} / \mathrm{mol}$ obtained in the phase solubility study. The corresponding $\Delta G^{0}$ value calculated according to equation (2) was $-31.73 \mathrm{~kJ} / \mathrm{mol}$.

\section{Preparation and characterization of RAABCD}

A drug can often be molecularly encapsulated by several methods, eg, coprecipitation, sonication, and kneading.
Judgment of the suitability of a given preparation method is based on several considerations, including the properties of the host and guest molecules, the type and amount of solvents, and the encapsulation effect. When RAABCD was prepared using coprecipitation or sonication, encapsulation was not successful (data not shown), which was probably attributable to the fact that rifaldazine undergoes hydrolysis and oxidation when exposed to high temperature and/or ultrasound. Further, considering the need for viable industrial production and the instability of rifaldazine in water (oxidation and hydrolysis reactions frequently occur because of the high reactivity between hydroxyl groups and amide bonds), referring to previous work ${ }^{11}$ and based on preparatory experiments, a solid-state grinding method was chosen to prepare the RAABCD. The preparation time of 30 minutes in our study is significantly shorter than the 5-8 hours documented in the US patent application. ${ }^{14}$ The water solubility of RAABCD was $13.21 \pm 0.13 \mathrm{mmol} / \mathrm{L}(\mathrm{n}=5)$, which was 4.4 times higher than that of free rifaldazine $(3.00 \pm 0.16 \mathrm{mmol} / \mathrm{L}$, $\mathrm{n}=5$ ), ie, the solubilization effect of RAABCD obtained here was solubility of rifaldazine was increased by two-fold compared with the method cited in the US patent application. In addition, as far as the method for improving solubility is concerned, molecular inclusion complexation technology might be equally or more effective and much simpler and
A

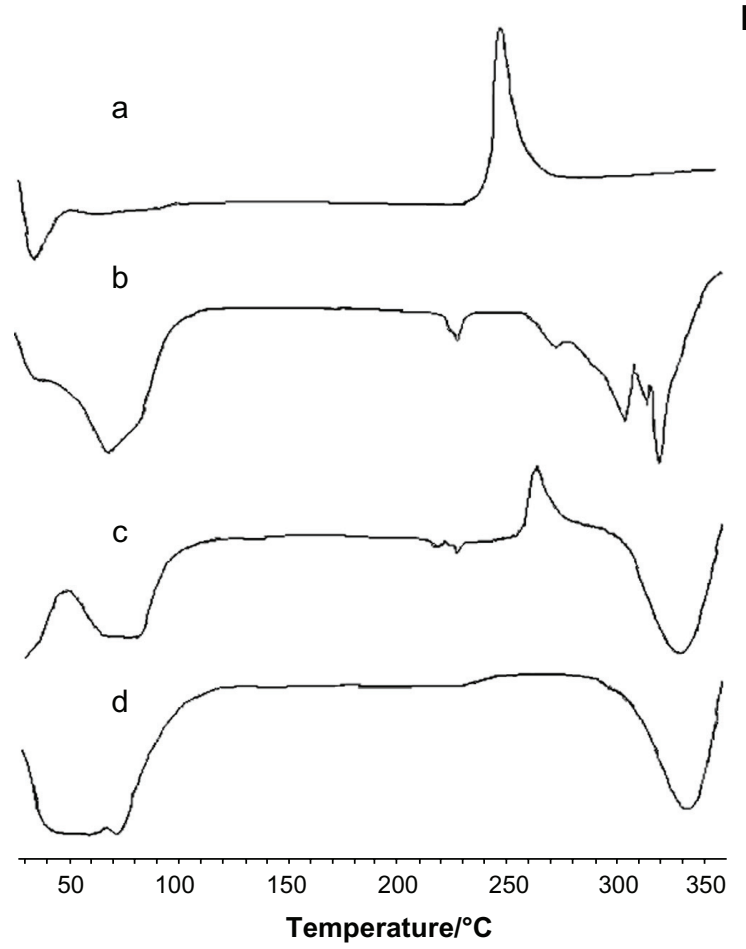

B

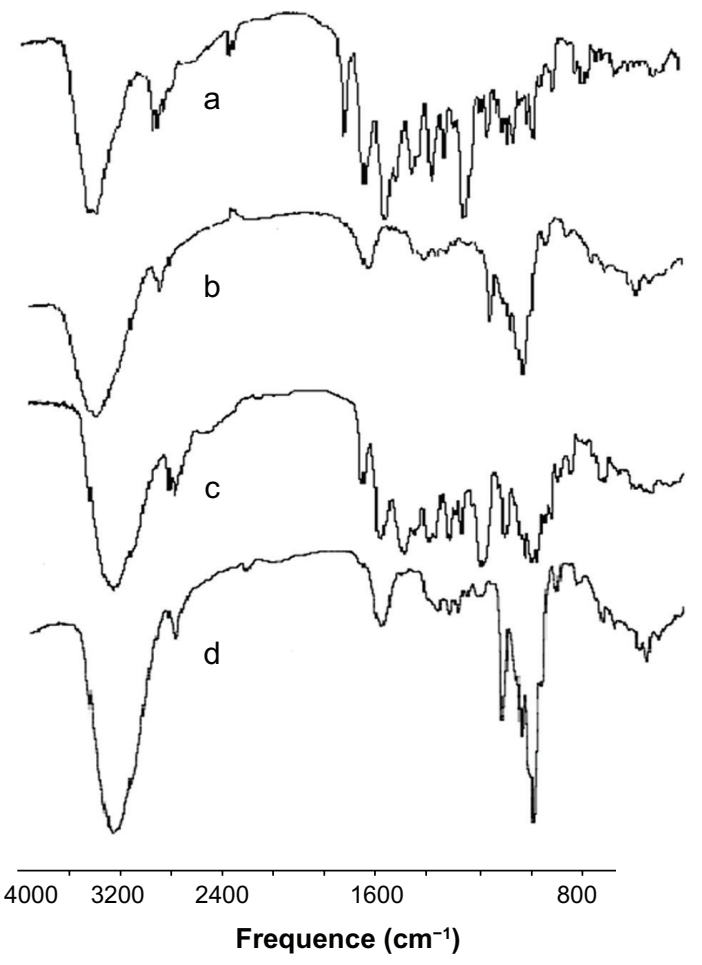

Figure 3 Differential scanning calorimetry $(\mathbf{A})$ and Fourier transform infrared spectra $(\mathbf{B})$ of rifaldazine (a), $\beta$-cyclodextrin (b), physical mixture (c), and RAABCD (d). Abbreviation: RAABCD, $\beta$-cyclodextrin molecular inclusion complexes of rifaldazine. 
easier for production scale-up than other approaches, such as emulsification and phospholipid complexation. ${ }^{25,26}$

Formation of RAABCD was confirmed by differential scanning calorimetry and FTIR spectroscopy. As shown in Figure $3 \mathrm{~A}$, the differential scanning calorimetry thermogram for rifaldazine showed a sharp peak at $259^{\circ} \mathrm{C}$, corresponding to the melting point of rifaldazine. Compared with free rifaldazine, the physical mixture of rifaldazine and $\beta$-cyclodextrin showed an intrinsic endothermal peak for rifaldazine at the same temperature with lower intensity, which might be partly due to the dilution of rifaldazine with $\beta$-cyclodextrin. However, in RAABCD, this characteristic peak for rifaldazine almost disappeared, suggesting that the rifaldazine molecule might be mainly enclosed within the inner cavity of $\beta$-cyclodextrin. Similarly, the interaction between rifaldazine and $\beta$-cyclodextrin could be confirmed by the observed shifts in wave number of peaks in the FT-IR spectra. As shown in Figure 3B, the FTIR spectrum of rifaldazine showed peaks at $3476 \mathrm{~cm}^{-1}, 2881 \mathrm{~cm}^{-1}, 1726 \mathrm{~cm}^{-1}$, $1646 \mathrm{~cm}^{-1}$, and $1568 \mathrm{~cm}^{-1}$, corresponding to $\mathrm{OH}, \mathrm{N}-\mathrm{CH}_{3}$, acetyl $\mathrm{C}-\mathrm{O}$, furanone $\mathrm{C}-\mathrm{O}$, and amide $\mathrm{C}-\mathrm{O}$, respectively, ${ }^{14}$ while the peaks for $\beta$-cyclodextrin at $3434 \mathrm{~cm}^{-1}, 2924 \mathrm{~cm}^{-1}$, $1649 \mathrm{~cm}^{-1}, 1158 \mathrm{~cm}^{-1}$, and $1080 \mathrm{~cm}^{-1}$ were assigned to
$\mathrm{O}-\mathrm{H}$ stretching vibration, $\mathrm{C}-\mathrm{H}$ stretching vibration, $\mathrm{H}-\mathrm{O}-\mathrm{H}$ bending vibration, $\mathrm{C}-\mathrm{O}$ stretching vibration, and $\mathrm{C}-\mathrm{O}-\mathrm{C}$ stretching vibration, respectively. The FTIR spectrum of RAABCD was quite different from that of rifaldazine or the additive effects of rifaldazine and $\beta$-cyclodextrin, indicating that there might be some molecular interaction between rifaldazine and $\beta$-cyclodextrin (for example, the methylpiperazine group of rifaldazine might be entrapped in the cavity of $\beta$-cyclodextrin, accounting for the rifaldazine peaks missing in the spectrum for the complex).

As depicted in Figure 4, the morphologies of RAABCD, rifaldazine, $\beta$-cyclodextrin, and the physical mixture were observed by optical microscopy. Free rifaldazine and $\beta$-cyclodextrin had columnar and irregular (quadrate) shapes, respectively, while the physical mixture was the simple adduct of free rifaldazine and $\beta$-cyclodextrin. In contrast with the physical mixture, RAABCD showed an irregular and amorphous shape, suggesting the formation of a molecular inclusion complex containing rifaldazine.

\section{Computer modeling}

The molecular structures of rifaldazine and $\beta$-cyclodextrin were simulated separately using the MOPAC2004 program in the
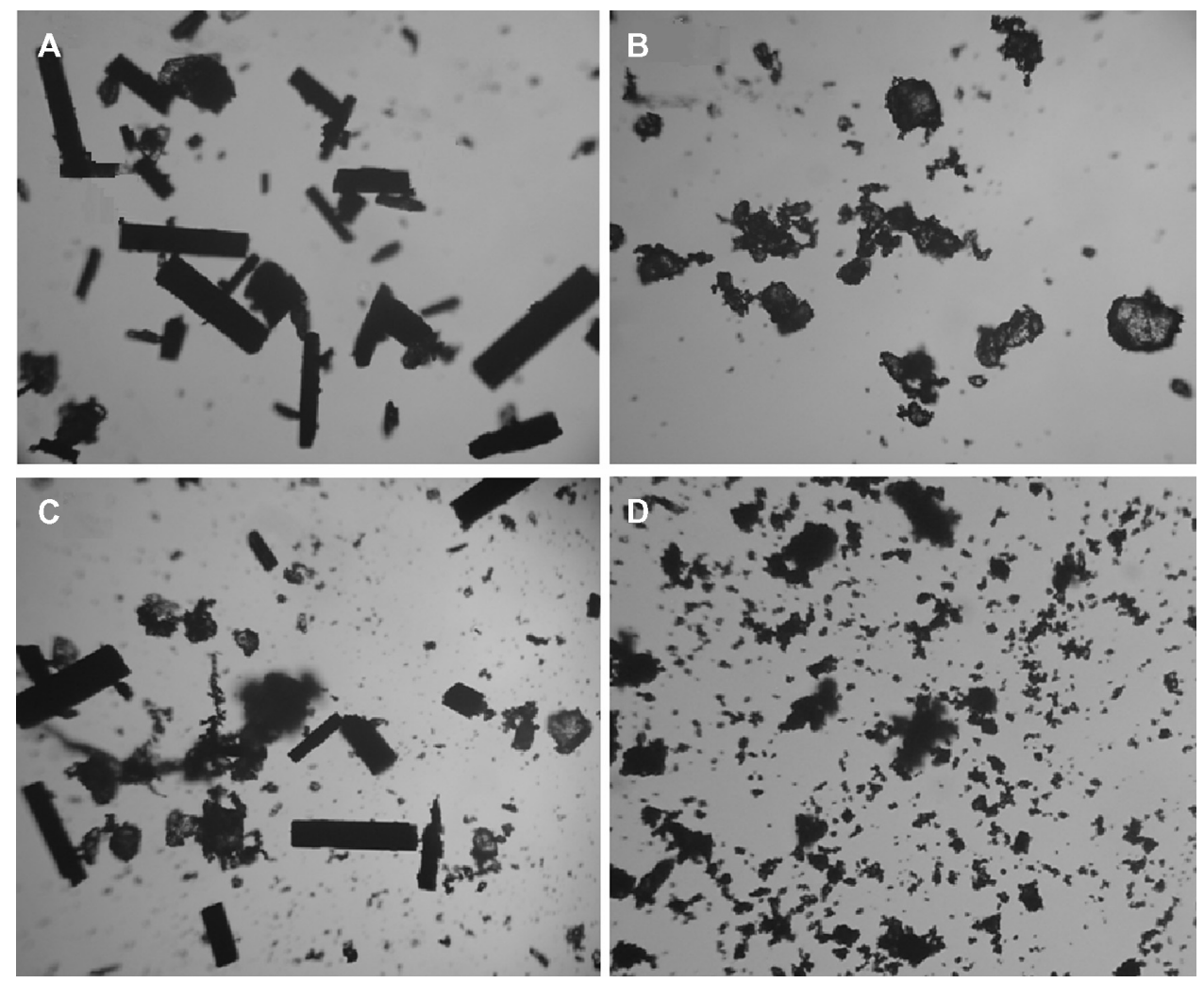

Figure 4 Microscopic photographs $(\times 400)$ of rifaldazine $(\mathbf{A}), \beta$-cyclodextrin $(\mathbf{B})$, physical mixture $(\mathbf{C})$, and RAABCD (D). Abbreviation: RAABCD, $\beta$-cyclodextrin molecular inclusion complexes of rifaldazine. 
computer-aided software system (CAChe 6.18 Worksystem Pro). The clathrate structure of RAABCD was constructed using a molecular docking approach. Interaction energies were computed for rifaldazine, approaching from the methylpiperazine group, to identify the most probable optimal configuration of the complex (see Figure 5). The corresponding binding energies with their electrostatic and Van der Waals contributions are shown in Table 1. The dominant driving force of the complexation process between rifaldazine and $\beta$-cyclodextrin appeared to be Van der Waals forces and hydrogen bonds. The positive binding energy value indicate the spontaneity and feasibility of the complexation of rifaldazine and $\beta$-cyclodextrin, which is in agreement with the result obtained using the abovementioned thermodynamic approach (ie, method of calculating change in Gibbs free energy).

\section{Antibacterial activity}

RAABCD and free rifaldazine were tested-n Gram-positive (S. aureus) and Gram-negative bacteria (E. coli) using the broth macrodilution method. Bacteria flourished in pure MuellerHinton culture medium (positive reference). Minimum inhibitory concentrations for RAABCD and free rifaldazine were $0.125 \mu \mathrm{g} / \mathrm{mL}$ and $0.125 \mu \mathrm{g} / \mathrm{mL}$ for $S$. aureus, and $32 \mu \mathrm{g} / \mathrm{mL}$ and $16 \mu \mathrm{g} / \mathrm{mL}$ for $E$. coli, respectively. These data suggest that RAABCD has good antibacterial activity against $S$. aureus and $E$. coli. In an earlier study, the mean minimum inhibitory concentrations of a randomly methylated RAABCD complex, RAAHCD complex, and free rifaldazine were reported to be $26.3 \mu \mathrm{g} / \mathrm{mL}, 5.63 \mu \mathrm{g} / \mathrm{mL}$, and $15 \mu \mathrm{g} / \mathrm{mL}$ for Acinetobacter baumannii CIP7010T, respectively. ${ }^{8}$ The activity of the rifaldazine complex for bacteria clearly decreased in the order of S. aureus, E. coli, and A. baumannii. The difference between the minimum inhibitory concentrations of free rifaldazine and its molecular inclusion complex indicate a complicated relationship between the drug delivery system and type of bacteria.

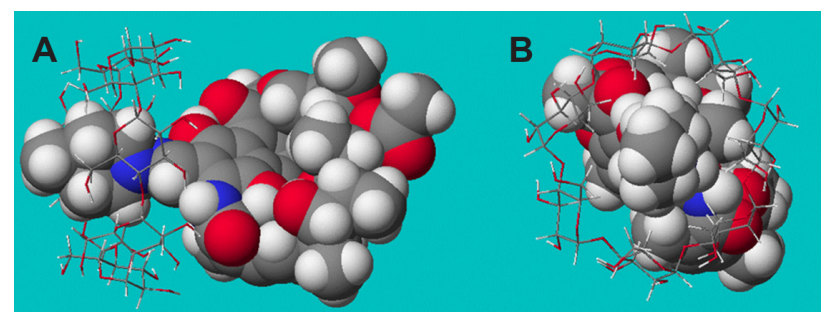

Figure $\mathbf{5}$ Side (A) and front (B) views of the most probable RAABCD configurations obtained for the I:I complexes.

Notes: Rifaldazine is represented as a CPK model, while $\beta$-cyclodextrin is represented as a ball-and-stick model. The rifaldazine and $\beta$-cyclodextrin molecules consisted of different atoms of hydrogen (white color), carbon (gray color), oxygen (red color), and nitrogen (blue color).

Abbreviation: RAABCD, $\beta$-cyclodextrin molecular inclusion complexes of rifaldazine.
Table I Molecular modeling of interaction energies corresponding to optimal configurations of RAABCD

\begin{tabular}{|c|c|c|c|}
\hline \multirow[t]{2}{*}{ Parameter } & \multicolumn{3}{|c|}{ Energy (kcal/mol) } \\
\hline & $\begin{array}{l}\text { Before } \\
\text { complexing } \\
\left(E_{1}\right)\end{array}$ & $\begin{array}{l}\text { After } \\
\text { complexing } \\
\left(E_{2}\right)\end{array}$ & $\begin{array}{l}\text { Binding } \\
\text { energy* } \\
\left(E_{\text {binding }}=E_{1}-E_{2}\right)\end{array}$ \\
\hline Van der & 116.230 & 105.446 & 10.784 \\
\hline \multicolumn{4}{|l|}{ Waals } \\
\hline Electrostatics & 275.242 & 273.203 & 2.039 \\
\hline Hydrogen & 3.735 & -3.364 & 7.099 \\
\hline \multicolumn{4}{|l|}{ bond } \\
\hline Stretch & 20.329 & 20.436 & -0.107 \\
\hline Angle & 62.245 & 63.745 & -1.5 \\
\hline Stretch bend & 3.179 & 3.105 & 0.074 \\
\hline Dihedral & 48.907 & 46.481 & 2.426 \\
\hline Improper & 0.897 & 0.795 & 0.102 \\
\hline \multicolumn{4}{|l|}{ torsion } \\
\hline Torsion & -3.200 & -2.955 & -0.245 \\
\hline \multicolumn{4}{|l|}{ stretch } \\
\hline Bend bend & 0.514 & 0.605 & -0.091 \\
\hline Total energy & 528.0782 & 507.4965 & 20.5817 \\
\hline
\end{tabular}

Note: *Binding energy was equal to the energy difference between the energy level before complexing and that after complexing.

Abbreviation: RAABCD, $\beta$-cyclodextrin molecular inclusion complexes containing rifaldazine.

\section{Conclusion}

The hydrophobic drug, rifaldazine, could be successfully molecularly encapsulated into the cavity of $\beta$-cyclodextrin to form RAABCD with better solubility (4.4 times that of free rifaldazine) in a short time frame (30 minutes) using a solidstate grinding method. The inclusion ratio, binding constant, and change in Gibbs free energy determined by a phase solubility diagram and/or ultraviolet-visible spectroscopy were $1: 1$, 288.33/261.33 L/mol, and -32.29/-31.73 kJ/mol, respectively. Differential scanning calorimetry and FTIR spectroscopy of RAABCD confirmed that there was a molecular interaction between rifaldazine and $\beta$-cyclodextrin. The morphological differences between irregular and amorphous-shaped RAABCD and columnar-shaped rifaldazine further confirm the molecular encapsulation of rifaldazine. The most probable optimal configuration for RAABCD with a $1: 1$ stoichiometry was simulated via computer modeling. Broth macrodilution tests indicate that RAABCD had good antibacterial activity. Therefore, RAABCD might be a preferred alternative for oral administration of rifaldazine when used to treat various bacterial infections. Further studies are necessary to evaluate the in vivo pharmacokinetics, biodistribution, and pharmacodynamics of RAABCD.

\section{Acknowledgments}

This research was partially supported by grants from the National Natural Science Foundation of China (30973645), 
Specialized Research Fund for the Doctoral Program of Higher Education (20095503120008), Chongqing Natural Science Foundation (CSTC2012JJB10027), and Chongqing Education Committee Fund (Excellent University Personnel Financial Aid Plan, KJ120321).

\section{Disclosure}

The authors report no conflicts of interest in this work.

\section{References}

1. Dooley KE, Bliven-Sizemore EE, Weiner M, et al. Safety and pharmacokinetics of escalating daily doses of the antituberculosis drug rifapentine in healthy volunteers. Clin Pharmacol Ther. 2012;91:881-888.

2. Spellberg B, Lipsky BA. Systemic antibiotic therapy for chronic osteomyelitis in adults. Clin Infect Dis. 2012;54:393-407.

3. Zalmanovici Trestioreanu A, Fraser A, Gafter-Gvili A, et al. Antibiotics for preventing meningococcal infections. Cochrane Database Syst Rev. 2011;8:CD004785.

4. [No authors listed]. Drugs for tuberculosis. Treat Guidel Med Lett. 2012;10:29-36.

5. Steingart KR, Jotblad S, Robsky K, et al. Higher-dose rifampin for the treatment of pulmonary tuberculosis: a systematic review. Int J Tuberc Lung Dis. 2011;15:305-316.

6. Changsan N, Nilkaeo A, Pungrassami P, et al. Monitoring safety of liposomes containing rifampicin on respiratory cell lines and in vitro efficacy against Mycobacterium bovis in alveolar macrophages. J Drug Target. 2009;17:751-762.

7. Quenelle DC, Staas JK, Winchester GA, et al. Efficacy of microencapsulated rifampin in Mycobacterium tuberculosis-infected mice. Antimicrob Agents Chemother. 1999;43:1144-1151.

8. Tewes F, Brillault J, Couet W, et al. Formulation of rifampicincyclodextrin complexes for lung nebulization. J Control Release. 2008;129:93-99.

9. Manca ML, Manconi M, Valenti D, et al. Liposomes coated with chitosan-xanthan gum (chitosomes) as potential carriers for pulmonary delivery of rifampicin. $J$ Pharm Sci. 2012;101:566-575.

10. Gaur PK, Mishra S, Gupta VB, et al. Targeted drug delivery of rifampicin to the lungs: formulation, characterization, and stability studies of preformed aerosolized liposome and in situ formed aerosolized liposome. Drug Dev Ind Pharm. 2010;36:638-646.

11. Loftsson T, Brewster ME. Cyclodextrins as functional excipients: methods to enhance complexation efficiency. J Pharm Sci. 2012;101: 3019-3032.
12. Laza-Knoerr AL, Gref R, Couvreur P. Cyclodextrins for drug delivery. J Drug Target. 2010;18:645-656.

13. Loftsson T, Brewster ME. Pharmaceutical applications of cyclodextrins: basic science and product development. J Pharm Pharmacol. 2010;62: $1607-1621$.

14. Rao KR, Bhanumathi N, Yadav JS, et al, inventors; Council of Scientific and Industrial Research, assignee. Inclusion complex of rifampicin, an anti-tubercular drug, with beta-cyclodextrin or 2-hydroxypropyl beta-cyclodextrin and a process thereof. United States patent US 7001893. February 21, 2006.

15. Ding PT. Cyclodextrin derivatives. In: He ZG, editor. Cyclodextrin Inclusion Complex Technology. Beijing, China: People's Medical Publishing House; 2008. Chinese.

16. Madan J, Baruah B, Nagaraju M, et al. Molecular cycloencapsulation augments solubility and improves therapeutic index of brominated noscapine in prostate cancer cells. Mol Pharm. 2012;9:1470-1480.

17. Higuchi T, Connors KA. Phase-solubility techniques. Adv Anal Chem Instrum. 1965;4:117-212.

18. Jiang Y, Sha X, Zhang W, et al. Complex of 9-nitro-camptothecin in hydroxypropyl-beta-cyclodextrin: in vitro and in vivo evaluation. Int J Pharm. 2010;397:116-121.

19. Barooah N, Mohanty J, Pal H, et al. Supramolecular assembly of Hoechst-33258 with cucurbit[7]uril macrocycle. Phys Chem Chem Phys. 2011;13:13117-13126.

20. Ma XQ, Ren Y, Fu XY. Research on camptothecin-HP- $\beta$-cyclodextrin inclusion. Chinese Journal of New Drugs. 2007;16:1385-1387. Chinese.

21. Zhang JQ, Liu J, Li XL, et al. Preparation and characterization of solid lipid nanoparticles containing silibinin. Drug Deliv. 2007;14: 381-387.

22. Tan QY, Hu NN, Liu GD, et al. Role of a novel pyridostigmine bromidephospholipid nanocomplex in improving oral bioavailability. Arch Pharm Res. 2012;35:499-508.

23. Zhang JQ, Zhang ZR, Yang H, et al. Lyophilized paclitaxel magnetoliposomes as a potential drug delivery system for breast carcinoma via parenteral administration: in vitro and in vivo studies. Pharm Res. 2005;22:573-583.

24. Klancnik A, Piskernik S, Jersek B, et al. Evaluation of diffusion and dilution methods to determine the antibacterial activity of plant extracts. J Microbiol Methods. 2010;81:121-126.

25. Kotta S, Khan AW, Pramod K, et al. Exploring oral nanoemulsions for bioavailability enhancement of poorly water-soluble drugs. Expert Opin Drug Deliv. 2012;9:585-598.

26. Tan Q, Liu S, Chen X, et al. Design and evaluation of a novel evodiamine-phospholipid complex for improved oral bioavailability. AAPS Pharm Sci Tech. 2012;13:534-547.
International Journal of Nanomedicine

\section{Publish your work in this journal}

The International Journal of Nanomedicine is an international, peerreviewed journal focusing on the application of nanotechnology in diagnostics, therapeutics, and drug delivery systems throughout the biomedical field. This journal is indexed on PubMed Central, MedLine, CAS, SciSearch ${ }^{\circledR}$, Current Contents ${ }^{\circledR} /$ Clinical Medicine,

\section{Dovepress}

Journal Citation Reports/Science Edition, EMBase, Scopus and the Elsevier Bibliographic databases. The manuscript management system is completely online and includes a very quick and fair peer-review system, which is all easy to use. Visit http://www.dovepress.com/ testimonials.php to read real quotes from published authors. 